\title{
Financial Estimation of the Uncertainty in Medicine Using Present Value of Medical Fees and a Mortality Risk Prediction Model: a Retrospective Cohort Study
}

\author{
Hiroki Furuhata ${ }^{1,2}$ [Denji Araki $^{1} \cdot$ Taisuke Ogawa $^{1}$ \\ Received: 18 July 2021 / Accepted: 22 September 2021 / Published online: 1 October 2021 \\ (c) The Author(s), under exclusive licence to Springer Science+Business Media, LLC, part of Springer Nature 2021
}

\begin{abstract}
This study aimed to develop a method to enable the financial estimation of each patient's uncertainty without focusing on healthcare technology. We define financial uncertainty (FU) as the difference between an actual amount of claim (AC) and the discounted present value of the AC (DAC). DAC can be calculated based on a discounted present value calculated using a cash flow, a period of investment, and a discount rate. The present study considered these three items as AC, the length of hospital stay, and the predicted mortality rate. The mortality prediction model was built using typical data items in standard level electronic medical records such as sex, age, and disease information. The performance of the prediction model was moderate because an area under curve was approximately $85 \%$. The empirical analysis primarily compares the FU of the top 20 diseases with the actual AC using a retrospective cohort in the University of Miyazaki Hospital. The observational period is 5 years, from April 1, 2013, to March 31, 2018. The analysis demonstrates that the proportion of FU to actual AC is higher than $20 \%$ in low-weight children, patients with leukemia, brain tumor, myeloid leukemia, or non-Hodgkin's lymphoma. For these diseases, patients cannot avoid long hospitalization; therefore, the medical fee payment system should be designed based on uncertainty. Our method is both practical and generalizable because it uses a small number of data items that are required in standard electronic medical records. This method contributes to the decision-making processes of health policymakers.
\end{abstract}

Keywords Discounted present value $\cdot$ Electronic medical record $\cdot$ Mortality prediction model $\cdot$ Uncertainty

\section{Introduction}

\section{Background}

Regarding the development of health economics, uncertainty has been one of the most important issues in medicine for many years. In 1963, a classic study suggested that uncertainty is due to information or knowledge asymmetry between patients as consumers and medical staffs as

This article is part of the Topical Collection on Health Policy

Hiroki Furuhata

hiroki_furuhata@med.miyazaki-u.ac.jp

1 Department of Hospital Institutional Research, University of Miyazaki Hospital, 5200 Kibara Kiyotake-cho, Miyazaki 8891692, Japan

2 Graduate School of Medicine and Veterinary Medicine, University of Miyazaki, 5200 Kibara Kiyotake-cho, Miyazaki 8891692, Japan suppliers [1]. In other words, the medical knowledge of the staff is too difficult and complex for patients to understand. Another study explained that there are various types of uncertainty, such as diagnosis and administration [2]. Theoretical studies on the definition of uncertainty can be categorized into three types. The first is a systematic classification that subdivides uncertainty into three composite factors (personal, practical, and scientific) [3], from diseaseto patient-oriented [4], and other three types of uncertainty (conceptual, methodological, and ethical) [5]. The second is a qualitative approach that clarifies the uncertainty that clinicians often face, such as attention deficit hyperactivity disorder [6], primary health care [7], and prostate cancer [8]. The third is a specific theme to develop a new analytic method, such as evaluating the degree of an effect $[9,10]$.

Recently, cost-effective analysis was developed from multivariate sensitivity analysis using the Bayesian approach [11]. Almost all the existing research used a model-based approach by employing the following standard procedures: (1) model formularization, (2) parameter setting, and (3) 
effect estimation [12-23]. An artificial database was created for the estimation. Based on the results, various future simulations indicate the threat to the existing medical care system, such as social health insurance. Moreover, these studies contribute to building a guideline for health technology assessment (HTA). Thus, these studies can be called the model-technology-based approach.

However, only a few research articles have analyzed existing databases to evaluate medical uncertainty despite the importance of cost estimation of pharmacy services [24-26]. In addition, previous studies have not evaluated each patient's uncertainty because they focused on individuals by following the guideline of HTA [27]. The use of observational real-world data recorded by each patient has been suggested in the past 10 years [11]. Since the secondary use of electronic medical records (EMRs) as real-world data is now imminent, it is essential to integrate methods with concrete data items that are mandatory to record in the standard level EMRs in estimating uncertainty. After reviewing the existing studies, the present research recommends the data-patient-based approach explained below.

\section{Study objective}

The objective of the present study is to develop a method to estimate the financial uncertainty (FU) of each patient based on a discounted present value (DPV) - one of the most popular methods in economics. This method will be applicable to standard EMRs; it uses only three items-the AC of medical fees, length of hospital stay (LHS, calculated as days), and predicted mortality rate (PMR). Based on a prediction model, some explorative variables that can be used to explain patients' condition were employed from existing EMRs to estimate the PMR.

\section{Methods}

\section{Study design and participants}

A retrospective cohort for data analysis was constructed using EMRs of the University of Miyazaki Hospital. The study period is 5 years, from April 1, 2013 to March 31, 2018. The use of these records was approved by the Committee of Medical Ethics, University of Miyazaki (ethics approval number O-0758). The following two raw databases were used to create the cohort: (1) patient information, which includes the date of hospitalization and discharge as well as patients' characteristics, such as sex, age, and disease information, and (2) claim information, which includes the $\mathrm{AC}$ of the social health insurance system in Japan.

Figure 1 shows the process of cohort creation. The patient information was recorded by the patient identification (patient
ID) and the date of hospitalization implemented as the unique key of the cohort. Furthermore, the mortality was evaluated at only the present hospitalization (date of hospitalization is 1 in Fig. 1) because previous hospitalization can be considered that patients didn't die. On the other hand, the claim information was summarized by the patient ID and the date of hospitalization (called the summarized claim information).

After the preparation of these databases above, the cohort was created by merging the patient information and the summarized claim information. With this data merging, there were two exclusion criteria as follows: unmerged data and missing values in explorative variables. As a result of data merging, two types of the cohort were created (DS1 and DS2). DS1 was recorded by the patient ID by keeping information only about the present hospitalization to build a mortality risk prediction model. As the evaluation of the mortality was implemented at only the present hospitalization, it was necessary for appropriate model building to use records about only the present hospitalization. On the other hand, DS2 keeps all records to estimate FU by each hospitalization during the observation period.

Furthermore, DS1 and DS2 were divided into two subgroups, new and existing groups. These groups were allocated by whether each hospitalization can refer to information about the previous hospitalization. For example, the patient ID 1 in Fig. 1 records both the new group at the date of hospitalization 2 that cannot refer to the date 3 and the existing group at the date 1 that can refer to the date 2 . These groups were implemented because prospective variables for model building differed according to whether patients can use information about the previous hospitalization.

\section{Outcome measure}

According to a fundamental textbook in economics [28], DPV can be calculated using the formula for estimating uncertainty at different times as follows:

$D P V=\frac{c}{(1+r)^{t}}$

where $c$ is the cash flow at $t$ years (called a future value); $r$ is a discount rate, and $t$ is the period of investment (years). The present study aims to convert this formula to calculate a discounted AC (DAC) as follows:

$D A C=\frac{c_{0}}{\left(1+p_{0} / l_{0}\right)^{l_{1}}}$

where $c_{0}$ is the future value of the $\mathrm{AC} ; p_{0}$ is the PMR used as the discount rate; $l_{0}$ is the mean LHS in the cohort that is used to convert each $p_{0}$ to daily values (called a daily PMR (DPMR)), and $l_{1}$ is the actual LHS of each hospitalization as the number of exposure days to the treatment risk. The 
Fig. 1 Data processing flowchart

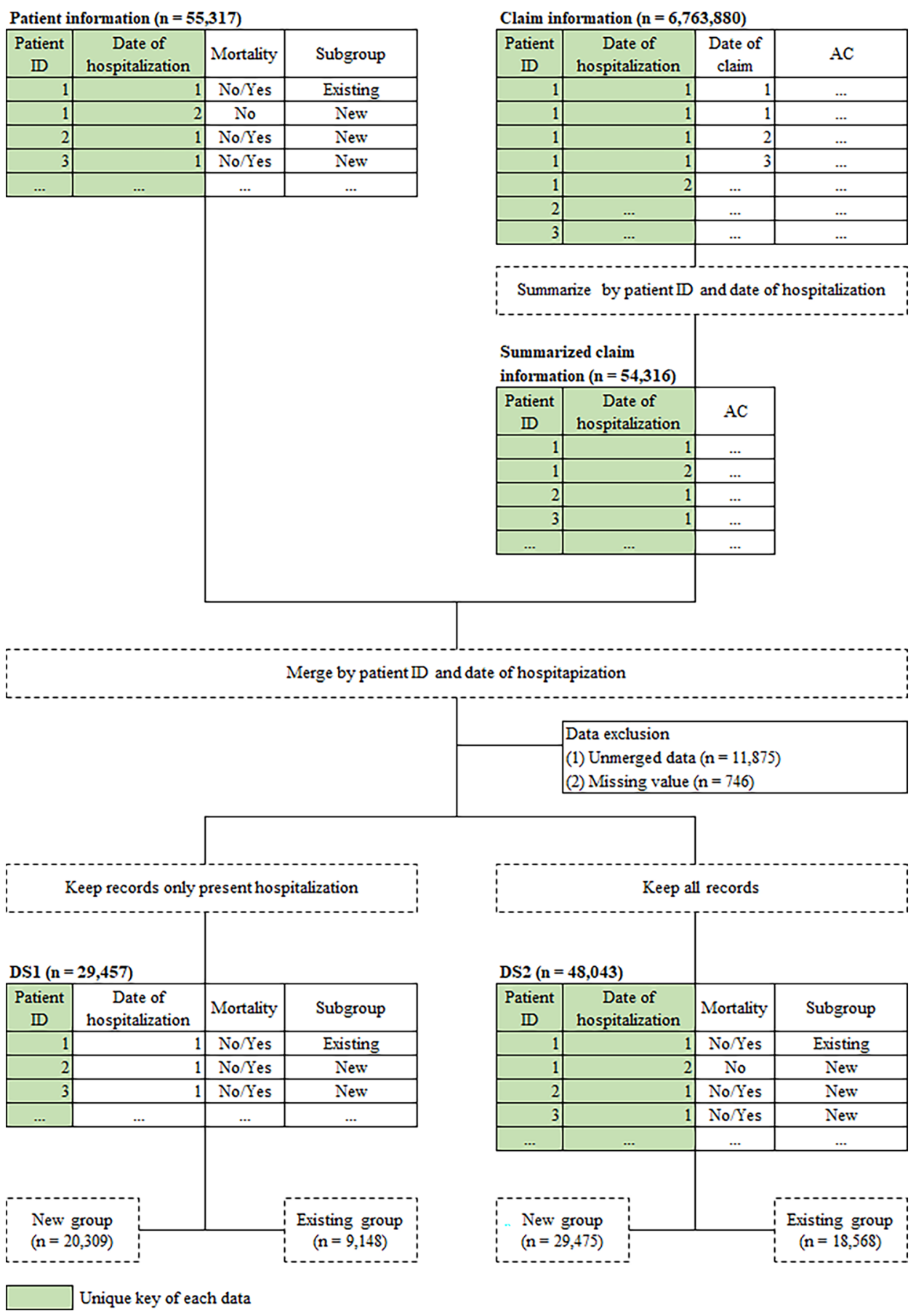

primary outcome measure is $\mathrm{FU}$, which is the difference between the actual AC and DAC.

\section{Mortality risk prediction model}

The objective variable for the risk prediction model is mortality because mortality is a typical hard endpoint for an acute medical condition in medical organizations, including the University of Miyazaki Hospital [29, 30]. Some previous studies have compared mortality to major patient characteristics (such as sex, age, and diagnosis of disease) [31], LHS [32], and readmission because patients have sarcopenia or not [33].

In this study, the following 15 explorative variables were created to build the prediction model: (1) sex; (2) age; (3) body mass index (BMI); (4) smoke (yes or no); (5) activities of daily living ((ADL) yes or no); (6) Japan Coma Scale ((JCS) yes or no); (7) cancer information (yes or no); (8) operation (yes or no); (9) plan change (yes or no); (10) comorbidity (yes or no); (11) post-hospital disease (yes or 
no); (12) ADL transition (no to no, no to yes, yes to no, or yes to yes); (13) JCS transition (no to no, no to yes, yes to no, or yes to yes); (14) LHS (calculated as the date of discharge at last hospitalization minus date of last hospitalization plus 1); (15) passed time until present hospitalization ((PTUPH) calculated as the date of present hospitalization minus date of discharge at last hospitalization plus 1). The 1 st to 7 th variables were implemented on both the new and existing groups because they are extracted from information about only present hospitalization, which is before the intervention of the present hospitalization. The 8 th to 15 th variables were implemented on only the existing group because they can be extracted from information about the last hospitalization.

These explorative variables have been explained in detail. ADL was coded as a binary system as follows: no (patients with ADL code "2312132222," which means they need no assistance with ADL) or yes (otherwise). This code consists of ten digits that explain ten types of physical conditions, such as diet, excretion, and walking. If this code is "2312132222," patients have no difficulty with these ten points. JCS was coded as a binary system as follows: no (missing value or zero) or yes (otherwise). A plan change, which was created from our previous study [34], is as follows: "A plan change would be implemented if the ICD-10 of the main disease differs from that of the disease for which medical resources were implemented, or if there is existence of disease with secondary implementation of medical resources." Additionally, the ICD-10 means the 10th revision of the International Statistical Classification of Diseases and Related Health Problems. ADL or JCS transition was a comparison of hospitalization and discharge of the four categories above.

\section{Statistical methods}

The statistical analyses in the present study were divided into three parts. First, a crude mortality rate (CMR) was calculated using each explorative variable. While comparing the CMR, a chi-squared test was performed on all the categorical variables. Additionally, Student's t-test was conducted on four continuous variables_age, BMI, LHS, and PTUPH.

Second, a logistic regression model was built to predict the mortality rate using the 15 explorative variables. Despite the four continuous variables, the variable was always categorical because it reveals the clinical characteristics, such as childhood, adulthood, or elderly. The regression was conducted as both univariate and multivariate analyses. A variable is used in the multivariate model if, based on the recent standard procedure, its p-value is less than 0.25 in the univariate model [35]. An area under the curve (AUC) was implemented as supplemental information about this modelbuilding procedure. AUC is an area of a receiver operating characteristics curve that is drawn using a true positive rate (vertical axis) and a false positive rate (horizontal axis) [36].

Finally, the third part was to estimate FU using the DAC equation. When PMR is converted to daily value (called daily PMR (DPMR)), $l_{0}$ is 17.3 days (new group) and 19.0 days (existing group). The FU was estimated to evaluate the influence of the FU of each disease using three heading of ICD-10.

All statistical analyses were performed using SAS University Edition (SAS Institute Inc., NC, USA).

\section{Results}

Table 1 presents the number of patients and CMR of each of the 15 explorative variables.

Based on the variable selection using the univariate model (Table 2), the odds ratio (OR) of the multivariate model used to estimate the PMR were calculated (Table 3). Additionally, the AUC was calculated within a 95\% confidence interval as follows (in parentheses): (1) new group $=0.844(0.823,0.861)$ and $(2)$ existing group $=0.859$ $(0.842,0.878)$.

Table 4 presents the total actual AC of the top 20 diseases and compares the FU in both actual value amount and a percentage to the actual AC. In the table, five diseases are in bold because their rate of FU is higher than $20 \%$. The actual AC and the FU are USD 462,873 thousand and USD 40,638 thousand for all diseases, and USD 154,341 thousand and USD 17,017 thousand for the top 20 diseases.

\section{Discussion}

\section{Key result}

The results have both theoretical and clinical implications based on various statistical values, such as CMR, OR, AUC, the rate of FU, and mean LHS or DPMR (Tables 1, 2, 3 and 4). As indicated in Table 1 , in each category, there are differences in the CMR of the 15 explorative variables. In particular, JCS (yes for both groups), LHS (which is less than 28 in the existing group), and PTUPH (which is equal to or less than 7 in the existing group) have higher values than the other category, implying that patients must take emergency readmission if PTUPH is equal to or less than 7.

While building the model (Tables 2 and 3), five and 13 variables were used in the multivariate model for the new and existing groups, respectively. The present study does not discuss a validity of patient classification based on AUC of the prediction model such as a criterion of an inspection because the present study uses PMR as a characteristic value to estimate FU of each patient outside actual treatment. 
Table 1 List of the 15 explorative variables

\begin{tabular}{|c|c|c|c|c|}
\hline Variable & $\begin{array}{l}\text { Total } \\
(\mathrm{N}=29,457)\end{array}$ & $\begin{array}{l}\text { Death } \\
(\mathrm{n}=857)\end{array}$ & $\operatorname{CMR}(\%)$ & $P$ value \\
\hline (a) Participants in new group & 20,309 & 472 & 2.3 & - \\
\hline \multicolumn{5}{|l|}{ Sex } \\
\hline Male & 10,393 & 288 & 2.8 & \multirow[t]{2}{*}{$<.0001$} \\
\hline Female & 9,916 & 184 & 1.9 & \\
\hline \multicolumn{5}{|l|}{ Age (years) } \\
\hline $0-19$ & 2,898 & 47 & 1.6 & \multirow[t]{4}{*}{$<.0001$} \\
\hline $20-64$ & 8,407 & 124 & 1.5 & \\
\hline $65-74$ & 4,272 & 114 & 2.7 & \\
\hline $74<$ & 4,732 & 187 & 4.0 & \\
\hline \multicolumn{5}{|l|}{ BMI } \\
\hline$<18.5$ & 3,722 & 118 & 3.2 & \multirow[t]{6}{*}{0.0052} \\
\hline 18.5 to $<25.0$ & 11,327 & 252 & 2.2 & \\
\hline 25.0 to $<30.0$ & 4,179 & 85 & 2.0 & \\
\hline 30.0 to $<35.0$ & 832 & 14 & 1.7 & \\
\hline 35.0 to $<40.0$ & 174 & 2 & 1.1 & \\
\hline $40 \leq$ & 75 & 1 & 1.3 & \\
\hline \multicolumn{5}{|l|}{ Smoke } \\
\hline No & 14,283 & 272 & 1.9 & \multirow[t]{2}{*}{$<.0001$} \\
\hline Yes & 6,026 & 200 & 3.3 & \\
\hline \multicolumn{5}{|l|}{ ADL } \\
\hline No & 10,464 & 43 & 0.4 & \multirow[t]{2}{*}{$<.0001$} \\
\hline Yes & 9,845 & 429 & 4.4 & \\
\hline \multicolumn{5}{|l|}{ JCS } \\
\hline No & 18,195 & 214 & 1.2 & \multirow[t]{2}{*}{$<.0001$} \\
\hline Yes & 2,114 & 258 & 12.2 & \\
\hline \multicolumn{5}{|l|}{ Cancer information } \\
\hline No & 17,352 & 383 & 2.2 & \multirow[t]{2}{*}{0.0074} \\
\hline Yes & 2,957 & 89 & 3.0 & \\
\hline (b) Participants in existing group & 9,148 & 385 & 4.2 & - \\
\hline \multicolumn{5}{|l|}{ Sex } \\
\hline Male & 4,883 & 248 & 5.1 & \multirow[t]{2}{*}{$<.0001$} \\
\hline Female & 4,265 & 137 & 3.2 & \\
\hline \multicolumn{5}{|l|}{ Age (years) } \\
\hline $0-19$ & 819 & 19 & 2.3 & \multirow[t]{4}{*}{0.0055} \\
\hline $20-64$ & 3,734 & 146 & 3.9 & \\
\hline $65-74$ & 2,383 & 120 & 5.0 & \\
\hline $74<$ & 2,212 & 100 & 4.5 & \\
\hline \multicolumn{5}{|l|}{ BMI } \\
\hline$<18.5$ & 1,519 & 117 & 7.7 & $<.0001$ \\
\hline 18.5 to $<25.0$ & 5,208 & 208 & 4.0 & \\
\hline 25.0 to $<30.0$ & 1,939 & 45 & 2.3 & \\
\hline 30.0 to $<35.0$ & 388 & 12 & 3.1 & \\
\hline 35.0 to $<40.0$ & 61 & 2 & 3.3 & \\
\hline $40 \leq$ & 33 & 1 & 3.0 & \\
\hline Smoke & & & & \\
\hline No & 5,892 & 230 & 3.9 & 0.0507 \\
\hline Yes & 3,256 & 155 & 4.8 & \\
\hline ADL & & & & \\
\hline No & 5,455 & 55 & 1.0 & $<.0001$ \\
\hline Yes & 3,693 & 330 & 8.9 & \\
\hline JCS & & & & \\
\hline No & 8,788 & 303 & 3.4 & $<.0001$ \\
\hline Yes & 360 & 82 & 22.8 & \\
\hline Cancer information & & & & \\
\hline No & 5,727 & 144 & 2.5 & $<.0001$ \\
\hline
\end{tabular}


Table 1 (continued)

\begin{tabular}{|c|c|c|c|c|}
\hline Variable & $\begin{array}{l}\text { Total } \\
(\mathrm{N}=29,457)\end{array}$ & $\begin{array}{l}\text { Death } \\
(\mathrm{n}=857)\end{array}$ & $\operatorname{CMR}(\%)$ & $\mathrm{P}$ value \\
\hline Yes & 3,421 & 241 & 7.0 & \\
\hline \multicolumn{5}{|l|}{ Operation } \\
\hline No & 4,701 & 238 & 5.1 & \multirow[t]{2}{*}{$<.0001$} \\
\hline Yes & 4,447 & 147 & 3.3 & \\
\hline \multicolumn{5}{|l|}{ Plan change } \\
\hline No & 1,241 & 30 & 2.4 & \multirow[t]{2}{*}{0.0007} \\
\hline Yes & 7,907 & 355 & 4.5 & \\
\hline \multicolumn{5}{|l|}{ Comorbidity } \\
\hline No & 618 & 10 & 1.6 & \multirow[t]{2}{*}{0.000} \\
\hline Yes & 8,530 & 375 & 4.4 & \\
\hline \multicolumn{5}{|c|}{ Post-hospital disease } \\
\hline No & 1,177 & 36 & 3.1 & \multirow[t]{2}{*}{0.0353} \\
\hline Yes & 7,971 & 349 & 4.4 & \\
\hline \multicolumn{5}{|c|}{ ADL transition } \\
\hline No to no & 4,628 & 133 & 2.9 & \multirow[t]{4}{*}{$<.0001$} \\
\hline Yes to no & 900 & 55 & 6.1 & \\
\hline No to yes & 998 & 37 & 3.7 & \\
\hline Yes to yes & 2,622 & 160 & 6.1 & \\
\hline \multicolumn{5}{|l|}{ JCS transition } \\
\hline No to no & 8,826 & 365 & 4.1 & \multirow[t]{4}{*}{0.3178} \\
\hline Yes to no & 233 & 15 & 6.4 & \\
\hline No to yes & 14 & 1 & 7.1 & \\
\hline Yes to yes & 75 & 4 & 5.3 & \\
\hline \multicolumn{5}{|l|}{ LHS (days) } \\
\hline$\leq 7$ & 2,861 & 65 & 2.3 & \multirow[t]{5}{*}{$<.0001$} \\
\hline 7 to $\leq 14$ & 2,583 & 97 & 3.8 & \\
\hline 14 to $\leq 21$ & 1,548 & 59 & 3.8 & \\
\hline 21 to $\leq 28$ & 776 & 41 & 5.3 & \\
\hline $28<$ & 1,380 & 123 & 8.9 & \\
\hline \multicolumn{5}{|c|}{ PTUPH (days) } \\
\hline$\leq 7$ & 370 & 37 & 10.0 & \multirow[t]{3}{*}{$<.0001$} \\
\hline 7 to $\leq 28$ & 1,794 & 96 & 5.4 & \\
\hline $28<$ & 6,984 & 252 & 3.6 & \\
\hline
\end{tabular}

$A D L$ Activities of daily living, BMI Body mass index, JCS Japan Coma Scale, LHS Length of hospital stay $P T U P H$ Passed time until present hospitalization

However, the performance of the model was moderate because AUC is approximately $85 \%$ in both groups.

As indicated in Table 4, the FU of each disease differs significantly. The rate of FU (the percentage of the FU to the actual AC) in the five diseases in bold is greater than $20 \%$ because there was a higher value in their DPMR values compared to the other 15 diseases that are not in bold. Individually, the DPMR of C71 (brain tumor) was remarkably higher than that of the other four diseases in bold because physical function would often be impaired. Namely, brain tumor patients recorded a higher DPMR because their ADL (one of the explorative variables) tended to be "yes" with a higher OR than the other variables. Next, the mean LHSs of P07 (low-weight child), C91 (lymphocytic leukemia), and C92 (myeloid leukemia) were remarkably longer than those of the other 15 diseases that are not in bold. The reason is different for P07 and others. It is difficult for $\mathrm{P} 07$ patients to decide on how long medical staff should keep treating them because they are akin to newborn babies under precarious conditions. However, as per clinical guidelines, patients with $\mathrm{C} 91$ or C92 must stay in a clean room for a long time because reinforced chemotherapy is often carried out on them [37-40]. Finally, the mean DPMR and LHS of C85 (non-Hodgkin's lymphoma) is less than those of the other four diseases in bold. However, the rate of FU is greater than $20 \%$ because the mean DPMR is higher than those of the 15 diseases that are not in bold. Although C 85 is similar to $\mathrm{C} 91$ or C92 as a blood cancer [41], the reason for the higher rate is different among C85, C91, and C92. 
Table 2 Odds ratio in the prediction model (univariate analysis)

\begin{tabular}{|c|c|c|c|c|c|}
\hline \multirow[t]{2}{*}{ Variable } & \multicolumn{3}{|l|}{ New group $(n=20,309)$} & \multicolumn{2}{|c|}{ Existing group $(\mathrm{n}=9,148)$} \\
\hline & OR $(95 \% \mathrm{CI})$ & & $P$ value & OR $(95 \% \mathrm{CI})$ & $P$ value \\
\hline \multicolumn{6}{|l|}{ Sex } \\
\hline Male & Ref & & & Ref & \\
\hline Female & $0.663(0.550,0.800)$ & $<.0001$ & & $0.620(0.501,0.767)$ & $<.0001$ \\
\hline \multicolumn{6}{|l|}{ Age (years) } \\
\hline $0-19$ & Ref & & & Ref & \\
\hline $20-64$ & $0.908(0.647,1.274)$ & 0.5766 & & $1.713(1.056,2.780)$ & 0.0293 \\
\hline $65-74$ & $1.663(1.180,2.344)$ & 0.0037 & & $2.233(1.367,3.647)$ & 0.0013 \\
\hline $74<$ & $2.496(1.807,3.448)$ & $<.0001$ & & $1.994(1.213,3.278)$ & 0.0065 \\
\hline \multicolumn{6}{|l|}{ BMI } \\
\hline$<18.5$ & Ref & & & Ref & \\
\hline 18.5 to $<25.0$ & $0.695(0.557,0.868)$ & 0.0013 & & $0.498(0.394,0.630)$ & $<.0001$ \\
\hline 25.0 to $<30.0$ & $0.634(0.478,0.841)$ & 0.0016 & & $0.285(0.200,0.404)$ & $<.0001$ \\
\hline 30.0 to $<35.0$ & $0.523(0.299,0.914)$ & 0.0230 & & $0.382(0.209,0.700)$ & 0.0018 \\
\hline 35.0 to $<40.0$ & $0.355(0.087,1.449)$ & 0.1490 & & $0.406(0.098,1.683)$ & 0.2142 \\
\hline $40 \leq$ & $0.413(0.057,2.994)$ & 0.3814 & & $0.374(0.051,2.764)$ & 0.3355 \\
\hline \multicolumn{6}{|l|}{ Smoke } \\
\hline No & Ref & & & Ref & \\
\hline Yes & $1.768(1.470,2.128)$ & $<.0001$ & & $1.231(0.999,1.516)$ & 0.0510 \\
\hline \multicolumn{6}{|l|}{$\mathrm{ADL}$} \\
\hline No & Ref & & & Ref & \\
\hline Yes & $11.042(8.060,15.126)$ & $<.0001$ & & $9.633(7.218,12.857)$ & $<.0001$ \\
\hline \multicolumn{6}{|l|}{ JCS } \\
\hline No & Ref & & & Ref & \\
\hline Yes & $11.683(9.687,14.091)$ & $<.0001$ & & $8.260(6.295,10.838)$ & $<.0001$ \\
\hline \multicolumn{6}{|c|}{ Cancer information } \\
\hline No & Ref & & & Ref & \\
\hline Yes & $1.375(1.088,1.737)$ & 0.0077 & & $2.938(2.379,3.629)$ & $<.0001$ \\
\hline \multicolumn{6}{|l|}{ Operation } \\
\hline No & & & & Ref & \\
\hline Yes & & & & $0.641(0.520,0.791)$ & $<.0001$ \\
\hline \multicolumn{6}{|l|}{ Plan change } \\
\hline No & & & & Ref & \\
\hline Yes & & & & $1.897(1.301,2.768)$ & 0.0009 \\
\hline \multicolumn{6}{|l|}{ Comorbidity } \\
\hline No & & & & Ref & \\
\hline Yes & & & & $2.793(1.483,5.259)$ & 0.0015 \\
\hline \multicolumn{6}{|c|}{ Post-hospital disease } \\
\hline No & & & & Ref & \\
\hline Yes & & & & $1.451(1.024,2.057)$ & 0.0363 \\
\hline \multicolumn{6}{|l|}{ ADL transition } \\
\hline No to no & & & & Ref & \\
\hline Yes to no & & & & $2.200(1.593,3.038)$ & $<.0001$ \\
\hline No to yes & & & & $1.301(0.898,1.886)$ & 0.1641 \\
\hline Yes to yes & & & & $2.196(1.736,2.779)$ & $<.0001$ \\
\hline \multicolumn{6}{|l|}{ JCS transition } \\
\hline No to no & & & & Ref & \\
\hline Yes to no & & & & $1.595(0.935,2.720)$ & 0.0863 \\
\hline No to yes & & & & $1.783(0.233,13.668)$ & 0.5778 \\
\hline Yes to yes & & & & $1.306(0.474,3.595)$ & 0.6054 \\
\hline \multicolumn{6}{|l|}{ LHS (days) } \\
\hline$\leq 7$ & & & & Ref & \\
\hline 7 to $\leq 14$ & & & & $1.678(1.220,2.309)$ & 0.0015 \\
\hline 14 to $\leq 21$ & & & & $1.704(1.192,2.438)$ & 0.0035 \\
\hline
\end{tabular}


Table 2 (continued)

\begin{tabular}{llllll}
\hline Variable & New group $(\mathrm{n}=20,309)$ & & Existing group $(\mathrm{n}=9,148)$ & \\
\cline { 2 - 3 } & OR $(95 \% \mathrm{CI})$ & P value & & OR $(95 \% \mathrm{CI})$ & P value \\
\hline 21 to $\leq 28$ & & & $2.399(1.610,3.577)$ & $<.0001$ \\
$28<$ & & & $4.209(3.094,5.726)$ & $<.0001$ \\
PTUPH (days) & & & Ref & \\
$\leq 7$ & & & $0.509(0.342,0.757)$ & 0.0009 \\
7 to $\leq 28$ & & & $0.337(0.235,0.484)$ & $<.0001$ \\
\hline
\end{tabular}

$A D L$ Activities of daily living, $B M I$ Body mass index, $C I$ Confidence interval, JCS Japan Coma Scale, $L H S$ Length of hospital stay, OR Odds ratio, PTUPH Passed time until present hospitalization

\section{Limitations}

The present study has two limitations. The first is a theoretical issue from the study design using a retrospective cohort. Since our databases could record only a few data items of patients' typical characteristics, such as sex, age, and disease, our results do not eliminate all confounding factors in compensation for the easy use of numerous participants.

The second is an insufficient discussion of the objective variable as the basis of the discount rate $\left(p_{0}\right)$. Because data were easily collected from our databases, the objective variable is patients' mortality. However, mortality is not always appropriate as an objective variable. Various outcomes do not relate to mortality but have a considerable negative influence on patients' quality of life [42, 43]. Furthermore, the use of extracorporeal membrane oxygenation would be necessary to estimate the uncertainty of the coronavirus disease of 2019 [44]. Although their information is more difficult to record in EMRs as part of routine processing than mortality, their information comprises an appropriate additional event for estimating the discount rate. Therefore, objective variables should be decided based on the aims of each individual study.

\section{Significance}

The primary contribution of this study is to develop a systematic method of estimate FU in medicine using DPV, one of the most fundamental economic methods. Although DPV is often calculated to estimate uncertainty in various industries, a method of uncertainty estimation in medicine has been developed by each patient. Our method can define FU in medicine as the difference between AC and DAC based on DPV. Therefore, the present study can contribute to analytic methods in health economics such as cost-effectiveness analysis.

In detail of the primary contribution, the practical value of our method is that it can contribute to decision-making in health policy worldwide, because of the following three novel reasons. First, our method is more systemic than that of previous studies because a few typical items (AC, LHS, and objective or explorative variables for model building) in standard EMRs are required to estimate FU; this means that the generalizability of the present study is high. Second, the method employs LHS as an exposure time of treatment risk in medicine but not an efficiency indicator. Although various research articles [45-49] have demonstrated the importance of decreasing LHS, the present study has discussed LHS from different perspectives. Finally, the practice of attaching too much importance to decreasing LHS is criticized herein because of the social health insurance system in Japanese acute medical organizations called the Diagnosis Procedure Combination (DPC) payment system. In the DPC payment system, the revenue (equal to the daily AC herein) decreases daily [50]. This system provides medical organizations with an incentive to decrease LHS to improve efficiency. Some research articles have demonstrated the positive influence of this system [51, 52]. However, our empirical analysis indicates that patients with some diseases (the five diseases in bold in Table 4) cannot avoid long-time hospitalization because of their uncertainty. Despite the incentive of the DPC payment system, these diseases require long-time hospitalization to maintain safety. Therefore, these diseases would be inappropriate for the DPC payment system. Thus, several diseases that have higher levels of uncertainty should be excluded from the DPC system (which is a daily comprehensive payment system according to each disease) to a volume payment system according to each treatment as a health policymaking issue.

Our secondary contribution is to improve the technique of model building. Our prediction model can predict a patient's potential risk at hospitalization but not the discharge time. Almost all research uses a prediction model, such as a logistic regression model, to evaluate the effectiveness of target treatment using all data item recorded during hospitalization. However, the explorative variables in our model are limited to items that can be recorded before treatment. Despite the difference in the data items in our model and the existing studies, our model has recorded a moderate level of AUC. 
Table 3 Odds ratio in the prediction model (multivariate analysis)

\begin{tabular}{|c|c|c|c|c|}
\hline \multirow[t]{2}{*}{ Variable } & \multicolumn{2}{|c|}{ New group $(n=20,309)$} & \multicolumn{2}{|c|}{ Existing group $(\mathrm{n}=9,148)$} \\
\hline & OR $(95 \% \mathrm{CI})$ & $P$ value & OR $(95 \% \mathrm{CI})$ & $P$ value \\
\hline \multicolumn{5}{|l|}{ Sex } \\
\hline Male & Ref & & Ref & \\
\hline Female & $0.895(0.730,1.097)$ & 0.2851 & $0.654(0.507,0.844)$ & 0.0011 \\
\hline \multicolumn{5}{|l|}{ Age (years) } \\
\hline $0-19$ & & & Ref & \\
\hline $20-64$ & & & $2.521(1.472,4.317)$ & 0.0008 \\
\hline $65-74$ & & & $2.468(1.430,4.262)$ & 0.0012 \\
\hline $74<$ & & & $1.854(1.079,3.186)$ & 0.0253 \\
\hline \multicolumn{5}{|l|}{ Smoke } \\
\hline No & Ref & & Ref & \\
\hline Yes & $1.783(1.455,2.185)$ & $<.0001$ & $0.886(0.686,1.144)$ & 0.3533 \\
\hline \multicolumn{5}{|l|}{ ADL } \\
\hline No & Ref & & Ref & \\
\hline Yes & $7.020(5.013,9.829)$ & $<.0001$ & $8.953(6.521,12.292)$ & $<.0001$ \\
\hline \multicolumn{5}{|l|}{ JCS } \\
\hline No & Ref & & Ref & \\
\hline Yes & $7.541(6.113,9.301)$ & $<.0001$ & $4.911(3.605,6.689)$ & $<.0001$ \\
\hline \multicolumn{5}{|c|}{ Cancer information } \\
\hline No & Ref & & Ref & \\
\hline Yes & $3.393(2.608,4.414)$ & $<.0001$ & $3.410(2.686,4.328)$ & $<.0001$ \\
\hline \multicolumn{5}{|l|}{ Operation } \\
\hline No & & & Ref & \\
\hline Yes & & & $0.605(0.477,0.767)$ & $<.0001$ \\
\hline \multicolumn{5}{|l|}{ Plan change } \\
\hline No & & & Ref & \\
\hline Yes & & & $1.703(1.037,2.797)$ & 0.0353 \\
\hline \multicolumn{5}{|l|}{ Comorbidity } \\
\hline No & & & Ref & \\
\hline Yes & & & $1.869(0.879,3.975)$ & 0.1043 \\
\hline \multicolumn{5}{|c|}{ Post-hospital disease } \\
\hline No & & & Ref & \\
\hline Yes & & & $0.650(0.410,1.033)$ & 0.0682 \\
\hline \multicolumn{5}{|c|}{ ADL transition } \\
\hline No to no & & & Ref & \\
\hline Yes to no & & & $1.115(0.782,1.590)$ & 0.5471 \\
\hline No to yes & & & $1.157(0.772,1.734)$ & 0.4800 \\
\hline Yes to yes & & & $0.927(0.698,1.231)$ & 0.6006 \\
\hline \multicolumn{5}{|l|}{ LHS (days) } \\
\hline$\leq 7$ & & & Ref & \\
\hline 7 to $\leq 14$ & & & $1.610(1.147,2.260)$ & 0.0059 \\
\hline 14 to $\leq 21$ & & & $1.680(1.145,2.465)$ & 0.0080 \\
\hline 21 to $\leq 28$ & & & $1.865(1.207,2.882)$ & 0.0050 \\
\hline $28<$ & & & $2.931(2.085,4.119)$ & $<.0001$ \\
\hline \multicolumn{5}{|c|}{ PTUPH (days) } \\
\hline$\leq 7$ & & & Ref & \\
\hline 7 to $\leq 28$ & & & $0.755(0.489,1.167)$ & 0.2063 \\
\hline $28<$ & & & $0.573(0.384,0.854)$ & 0.0062 \\
\hline
\end{tabular}

$A D L$ activities of daily living, $C I$ confidence interval, JCS Japan Coma Scale, LHS length of hospital stay, $O R$ odds ratio, $P T U P T$ passed time until present hospitalization 
Table 4 Financial uncertainty in the top 20 diseases, descending, sorted by AC

\begin{tabular}{|c|c|c|c|c|c|c|c|}
\hline $\begin{array}{l}\text { Heading } \\
\text { three of } \\
\text { ICD-10 }\end{array}$ & Disease name & $\begin{array}{l}\text { Total number of } \\
\text { hospitalizations }\end{array}$ & $\begin{array}{l}\text { AC } \\
\text { (thousand } \\
\text { USD) }\end{array}$ & $\begin{array}{l}\text { FU } \\
\text { (thousand } \\
\text { USD) }\end{array}$ & Rate of FU (\%) & $\begin{array}{l}\text { LHS (days) } \\
\text { Mean (SD) }\end{array}$ & $\begin{array}{l}\text { DPMR (\%) } \\
\text { Mean (SD) }\end{array}$ \\
\hline I71 & Aortic aneurysm or dissection & 655 & 15,935 & 509 & 3.2 & $19.2(19.8)$ & $0.11(0.18)$ \\
\hline P07 & Low-weight child & 357 & 15,286 & 3,980 & 26.0 & $59.3(70.0)$ & $0.31(0.25)$ \\
\hline $\mathrm{C} 34$ & Lung cancer & 1,490 & 13,033 & 860 & 6.6 & $18.2(18.6)$ & $0.21(0.32)$ \\
\hline C91 & Lymphocytic leukemia & 360 & 9,608 & 2,389 & 24.9 & $38.4(50.5)$ & $0.36(0.40)$ \\
\hline $\mathrm{C} 22$ & Liver cancer & 1,144 & 9,422 & 581 & 6.2 & $17.1(14.7)$ & $0.23(0.31)$ \\
\hline M16 & Hip joint disease & 564 & 9,208 & 120 & 1.3 & $21.2(9.9)$ & $0.05(0.07)$ \\
\hline C71 & Brain tumor & 275 & 8,594 & 3,004 & 35.0 & $49.2(96.9)$ & $0.69(0.84)$ \\
\hline $\mathrm{C} 15$ & Esophageal cancer & 758 & 7,766 & 932 & 12.0 & $24.9(28.7)$ & $0.28(0.37)$ \\
\hline C92 & Myeloid leukemia & 174 & 7,470 & 1,687 & 22.6 & $50.7(46.8)$ & $0.39(0.44)$ \\
\hline $\mathrm{I} 35$ & Non-rheumatic aortic valve disorder & 246 & 7,157 & 251 & 3.5 & $21.8(16.4)$ & $0.10(0.14)$ \\
\hline $\mathrm{C} 16$ & Gastric cancer & 912 & 6,720 & 422 & 6.3 & $16.3(15.6)$ & $0.23(0.31)$ \\
\hline $\mathrm{C} 25$ & Pancreatic cancer & 728 & 6,075 & 431 & 7.1 & $20.6(18.7)$ & $0.24(0.36)$ \\
\hline $\mathrm{I} 20$ & Angina & 491 & 5,938 & 194 & 3.3 & $13.5(14.0)$ & $0.09(0.17)$ \\
\hline $\mathrm{C85}$ & Non-Hodgkin's lymphoma & 414 & 4,958 & 1,014 & 20.4 & $23.0(32.7)$ & $0.35(0.54)$ \\
\hline I47 & Paroxysmal tachycardia & 346 & 4,842 & 66 & 1.4 & $7.9(8.4)$ & $0.05(0.09)$ \\
\hline M48 & Other spine disorders & 496 & 4,766 & 119 & 2.5 & $18.1(13.6)$ & $0.08(0.10)$ \\
\hline I48 & Atrial fibrillation or flutter & 265 & 4,503 & 18 & 0.4 & $8.3(5.2)$ & $0.06(0.16)$ \\
\hline $\mathrm{I} 50$ & Heart failure & 281 & 4,462 & 331 & 7.4 & $24.7(21.2)$ & $0.25(0.30)$ \\
\hline H35 & Other retinopathy & 709 & 4,305 & 49 & 1.1 & $9.6(5.5)$ & $0.04(0.08)$ \\
\hline M17 & Knee osteoarthritis & 297 & 4,294 & 58 & 1.3 & $22.2(7.1)$ & $0.06(0.06)$ \\
\hline
\end{tabular}

$A C$ Amount of claim, DPMR Daily predicted mortality rate, FU Financial uncertainty, ICD-10 The 10th revision of the International Statistical Classification of Diseases and Related Health Problems, LHS Length of hospital stay, S, Standard deviation

Therefore, our model can be used as a real-time prediction model in a clinical workspace.

Abbreviation AC: Amount of claim; ID, Identification.

Acknowledgements The authors would like to thank Enago (www. enago.jp) for the English language review.

Authors' contributions Hiroki Furuhata: Conceptualization; data curation; formal analysis; Investigation; methodology; software; visualization; and writing - original draft. Kenji Araki: Funding acquisition; project administration; resources; supervision; validation; and writing - review and editing. Taisuke Ogawa: Data curation; validation; and writing - review and editing.

Funding The authors declare no external funding sources for this study.

\section{Declarations}

Ethics approval All procedures performed in studies involving human participants were in accordance with the ethical standards of the Committee of Medical Ethics, University of Miyazaki (ethics approval number, O-0758) and with the 1964 Helsinki declaration and its later amendments or comparable ethical standards.

Informed consent Informed consent was obtained by an opt-out method. Concretely, the authors noted details of this study on their website and asked participants to offer the authors not to use their information until the specified date. After this date, the authors could use information without patients' consent.

Consent for publication Not applicable.

Conflict of interest The authors declare that they have no conflict of interest.

\section{References}

1. Arrow, K. J., Uncertainty and the welfare economics of medical care. Am. Econ. Rev. 53:941-973, 1963.

2. Djulbegovic, B., Hozo, I., Greenland, S., Uncertainty in clinical medicine. In: Gabbay DM, Thagard P, Woods J (eds) Handbook of the Philosophy of Science: Philosophy of Medicine, Elsevier, North Holland, pp 299-356, 2011.

3. Pomare, C., Churruca, K., Ellis, L. A., et al A revised model of uncertainty in complex healthcare settings: a scoping review. $J$. Eval. Clin. Pract. 25:176-182, 2019. https://doi.org/10.1111/jep. 13079

4. Han, P. K. J., Klein, W. M. P., Arora, N. K., Varieties of uncertainty in health care: a conceptual taxonomy. Med. Decis. Making. 31:828-838, 2011.https://doi.org/10.1177/0272989X11393976

5. Han, P. K. J., Conceptual, methodological, and ethical problems in communicating uncertainty in clinical evidence. Med. Care. Res. Rev. 70(suppl):14S-36S, 2013. https://doi.org/10.1177/ 1077558712459361 
6. Rafalovich, A., Exploring clinician uncertainty in the diagnosis and treatment of attention deficit hyperactivity disorder. Sociol. Health Illn. 27:305-323, 2005. https://doi.org/10.1111/j.14679566.2005.00444.x

7. Williams, A., Sibbald, B., Changing roles and identities in primary health care: exploring a culture of uncertainty. J. Adv. Nurs. 29:737-745, 1999. https://doi.org/10.1046/j.1365-2648.1999. 00946.x

8. Pickles, K., Carter, S. M., Rychetnik, L., et al General practitioners' experiences of, and responses to, uncertainty in prostate cancer screening: insights from a qualitative study. PLoS One. 11:e0153299, 2016. https://doi.org/10.1371/journal.pone. 0153299

9. Price, M. J., Welton, N. J., Briggs, A. H., Ades, A. E., Model averaging in the presence of structural uncertainty about treatment effects: influence on treatment decision and expected value of information. Value Health. 14:205-218, 2011. https://doi.org/ 10.1016/j.jval.2010.08.001.

10. Barendregt, J. J., The effect size in uncertainty analysis. Value Health. 13:388-391, 2010. https://doi.org/10.1111/j.1524-4733. 2009.00686.x

11. Mauskopf, J., Multivariable and structural uncertainty analyses for cost-effectiveness estimates: back to the future. Value Health. 22:570-574, 2019. https://doi.org/10.1016/j.jval.2018.11.013

12. Broekhuizen, H., Groothuis-Oudshoorn, C. G. M., Vliegenthart, R., et al Assessing lung cancer screening programs under uncertainty in a heterogeneous population. Value Health. 21:12691277, 2018. https://doi.org/10.1016/j.jval.2018.01.021

13. Bojke, L., Claxton, K., Sculpher, M., Palmer, S., Characterizing structural uncertainty in decision analytic models: a review and application of methods. Value Health. 12:739-749, 2009. https:// doi.org/10.1111/j.1524-4733.2008.00502.x

14. Sculpher, M., Claxton, K., Establishing the cost-effectiveness of new pharmaceuticals under conditions of uncertainty-when is there sufficient evidence?. Value Health. 8:433-446, 2005. https:// doi.org/10.1111/j.1524-4733.2005.00033.x

15. Towse, A., Fenwick, E., Uncertainty and cures: discontinuation, irreversibility, and outcomes-based payments: what is different about a one-off treatment?. Value Health. 22:677-683, 2019. https://doi.org/10.1016/j.jval.2019.03.013

16. Sharif, B., Wong, H., Anis, A. H., Kopec, J. A., A practical ANOVA approach for uncertainty analysis in population-based disease microsimulation models. Value Health. 20:710-717, 2017. https://doi.org/10.1016/j.jval.2017.01.002

17. Petersohn, S., Grimm, S. E., Ramaekers, B. L. T., et al Exploring the feasibility of comprehensive uncertainty assessment in health economic modeling: a case study. Value Health. 24:983994, 2021. https://doi.org/10.1016/j.jval.2021.01.004

18. Briggs, A. H., Weinstein, M. C., Fenwick, E. A., Karnon, J., Sculpher, M. J., Paltiel, A. D., on behalf of the ISPOR-SMDM Modeling Good Research Practices Task Force., Model parameter estimation and uncertainty: a report of the ISPOR-SMDM modeling good research practices task Force-6. Value Health. 15:835-842, 2012. https://doi.org/10.1016/j.jval.2012.04.014

19. De Mello-Sampayo, F., The timing and probability of treatment switch under cost uncertainty: an application to patients with gastrointestinal stromal tumor. Value Health. 17:215-222, 2014. https://doi.org/10.1016/j.jval.2013.12.008

20. Ramos, I. C., Maureen, P. M. H., Mölken., R. V., Al, M. J., Determining the impact of modeling additional sources of uncertainty in value-of-information analysis. Value Health. 18:100-109, 2015. https://doi.org/10.1016/j.jval.2014.09.003

21. Galani, C., Al, M., Schneider, H., Rutten, F. F., Uncertainty in decision-making: value of additional information in the costeffectiveness of lifestyle intervention in overweight and obese people. Value Health. 11:424-434, 2008. https://doi.org/10. 1111/j.1524-4733.2007.00284.x

22. Oostenbrink, J. B., Al, M. J., Oppe, M., Rutten-van Mölken, M. P., Expected value of perfect information: an empirical example of reducing decision uncertainty by conducting additional research. Value Health. 11:1070-1080, 2008. https://doi.org/10. 1111/j.1524-4733.2008.00389.x

23. Maire, N., Shillcutt, S. D., Walker, D. G., et al Cost-effectiveness of the introduction of a pre-erythrocytic malaria vaccine into the expanded program on immunization in sub-Saharan Africa: analysis of uncertainties using a stochastic individual-based simulation model of Plasmodium falciparum malaria. Value Health. 14:1028-1038, 2011. https://doi.org/10.1016/j.jval.2011.06.004

24. Shajarizadeh, A., Hollis, A., Price-cap regulation, uncertainty and the Price evolution of new pharmaceuticals. Health Econ. 24:966-977, 2015. https://doi.org/10.1002/hec.3075

25. Franken, M. G., Gaultney, J. G., Blommestein, H. M., et al Policymaker, please consider your needs carefully: does outcomes research in Relapsedor refractory multiple myeloma reduce policymaker uncertainty regarding value for money of bortezomib?. Value Health. 17:245-253, 2014. https://doi.org/10. 1016/j.jval.2013.12.009

26. Rognoni, C., Ciani, O., Sommariva, S., Tarricone, R., Real-world data for the evaluation of transarterial radioembolization versus sorafenib in hepatocellular carcinoma: a cost-effectiveness analysis. Value Health. 20:336-344, 2017. https://doi.org/10.1016/j. jval.2016.09.2397

27. Grimm, S. E., Pouwels, X., Ramaekers, B. L. T., et al Development and validation of the TRansparent uncertainty ASsessmenT (T.R.U.S.T.) tool for assessing uncertainties in health economic decision models. Pharmacoeconomics. 38:205-216, 2020. https:// doi.org/10.1007/s40273-019-00855-9

28. Varian, H. R., Microeconomic Analysis (3rd ed). W. W. Norton and Company, Inc., New York, 1992.

29. Meier, P., Hemingway, H., Lansky, A. J., et al The impact of the coronary collateral circulation on mortality: a meta-analysis. Eur. Heart J. 33:614-621, 2012. https://doi.org/10.1093/eurheartj/ ehr308

30. Shroyer, A. L. W., Coombs, L. P., Peterson, E. D., et al The Society of Thoracic Surgeons: 30-day operative mortality and morbidity risk models. Ann. Thorac. Surg. 75:1856-1864, 2003. https:// doi.org/10.1016/s0003-4975(03)00179-6

31. Rooney, T., Moloney, E. D., Bennett, K., O’Riordan, D., Silke, B., Impact of an acute medical admission unit on hospital mortality: a 5-year prospective study. Q. J. Med. 101:457-465, 2008. https://doi.org/10.1093/qjmed/hen025

32. Hall, W. B., Willis, L. E., Medvedev, S., Carson, S. S., The implications of long-term acute Care Hospital transfer practices for measures of in-hospital mortality and length of stay. Am. J. Respir. Crit. Care Med. 185:53-57, 2012. https://doi.org/10.1164/rccm. 201106-1084OC

33. Yang, M., Hu, X., Wang, H., et al Sarcopenia predicts readmission and mortality in elderly patients in acute care wards: a prospective study. J. Cachexia Sarcopenia Muscle. 8:251-258, 2017. https:// doi.org/10.1002/jcsm.12163

34. Furuhata, H., Araki, K., Ogawa, T., Event surrogate from clinical pathway completion to daily meal for availability extension using standard electronic medical records: a retrospective cohort study. J. Med. Syst. 45:33, 2021. https://doi.org/10.1007/ s10916-021-01714-x

35. Hickey, G. L., Dunning, J., Seifert, B., et al Statistical and data reporting guidelines for the European Journal of Cardio-Thoracic Surgery and the Interactive CardioVascular and Thoracic Surgery. Eur. J. Cardiothorac. Surg. 48:180-193, 2015. https://doi.org/10. 1093/ejcts/ezv168 
36. Fawcett, T., An introduction to ROC analysis. Pattern Recognit. Lett. 27:861-874, 2006. https://doi.org/10.1016/j.patrec.2005.10.010

37. Hoelzer, D., Bassan, R., Dombret, H., et al Acute lymphoblastic leukaemia in adult patients: ESMO Clinical Practice Guidelines for diagnosis, treatment and follow-up. Ann. Oncol. 27(suppl 5):v69v82, 2016. https://doi.org/10.1093/annonc/mdw025

38. Eichhorst, B., Robak, T., Montserrat, E., et al Chronic lymphocytic leukaemia: ESMO Clinical Practice Guidelines for diagnosis, treatment and follow-up. Ann. Oncol. 32:23-33, 2020. https:// doi.org/10.1016/j.annonc.2020.09.019

39. Heuser, M., Ofran, Y., Boissel, N., et al Acute myeloid leukaemia in adult patients: ESMO Clinical Practice Guidelines for diagnosis, treatment and follow-up. Ann. Oncol. 31:697-712, 2020. https://doi.org/10.1016/j.annonc.2020.02.018

40. Hochhaus, A., Saussele, S., Rosti, G., et al Chronic myeloid leukaemia: E.S.M.O. Clinical Practice Guidelines for diagnosis, treatment and follow-up. Ann. Oncol. 28:iv41-iv51, 2017. https:// doi.org/10.1093/annonc/mdx219

41. Buske, C., Hutchings, M., Ladetto, M., et al ESMO Consensus Conference on malignant lymphoma: general perspectives and recommendations for the clinical management of the elderly patient with malignant lymphoma. Ann. Oncol. 29:544-562, 2018. https://doi.org/10.1093/annonc/mdx413

42. Husseman, J., Mehta, R. P., Management of synkinesis. Facial Plast. Surg. 24:242-249, 2008. https://doi.org/10.1055/s-2008-1075840

43. Bauermeister, J. J., Shrout, P. E., Chávez, L., et al ADHD and gender: are risks and sequela of ADHD the same for boys and girls?. J. Child Psychol. Psychiatry. 48:831-839, 2007. https:// doi.org/10.1111/j.1469-7610.2007.01750.x

44. Hong, X., Xiong, J., Feng, Z., Shi, Y., Extracorporeal membrane oxygenation (ECMO): does it have a role in the treatment of severe COVID-19?. Int. J. Infect. Dis. 94:78-80, 2020. https:// doi.org/10.1016/j.ijid.2020.03.058

45. Peiris, C. L., Shields, N., Brusco, N. K., et al Additional Saturday rehabilitation improves functional independence and quality of life and reduces length of stay: a randomized controlled trial. $B M C$ Med. 11:198, 2013. https://doi.org/10.1186/1741-7015-11-198
46. Rees, E. M., Nightingale, E. S., Jafari, Y., et al COVID-19 length of hospital stay: a systematic review and data synthesis. BMC Med. 18:270, 2020. https://doi.org/10.1186/s12916-020-01726-3

47. Sung, K. H., Chung, C. Y., Lee, K. M., et al Application of clinical pathway using electronic medical record system in pediatric patients with supracondylar fracture of the humerus: a before and after comparative study. BMC Med. Inform. Decis. Mak. 13:87, 2013. https://doi.org/10.1186/1472-6947-13-87

48. Furuhata, H., Araki, K., Ogawa, T., Ikeda, M., Effect on completion of clinical pathway for improving clinical indicator: cases of hospital stay, mortality rate, and comprehensivevolume ratio. J. Med. Syst. 41:206, 2017. https://doi.org/10.1007/ s10916-017-0857-6

49. Furuhata, H., Araki, K., Ogawa, T., Causation between pathway completion and reduced hospital stay in patients with lung cancer: a retrospective cohort study using propensity score matching. J. Med. Syst. 44:105, 2020. https://doi.org/10.1007/ s10916-020-01570-1

50. Hayashida, K., Murakami, G., Matsuda, S., Fushimi, K., History and profile of diagnosis procedure combination (DPC) development of a real data collection system for acute inpatient care in Japan. J. Epidemiol. 31:1-11, 2021. https://doi.org/10.2188/jea. JE20200288

51. Kunisawa, S., Fushimi, K., Imanaka, Y., Reducing length of hospital stay does not increase readmission rates in early-stage gastric, colon, and lung cancer surgical cases in Japanese Acute Care Hospitals. PLoS One. 11:e0166269, 2016. https://doi.org/10.1371/ journal.pone.0166269

52. Wang, K., Li, P., Chen, L., et al Impact of the Japanese diagnosis procedure combination-based payment system in Japan. J. Med. Syst. 34:95-100, 2010. https://doi.org/10.1007/ s10916-008-9220-2

Publisher's Note Springer Nature remains neutral with regard to jurisdictional claims in published maps and institutional affiliations. 